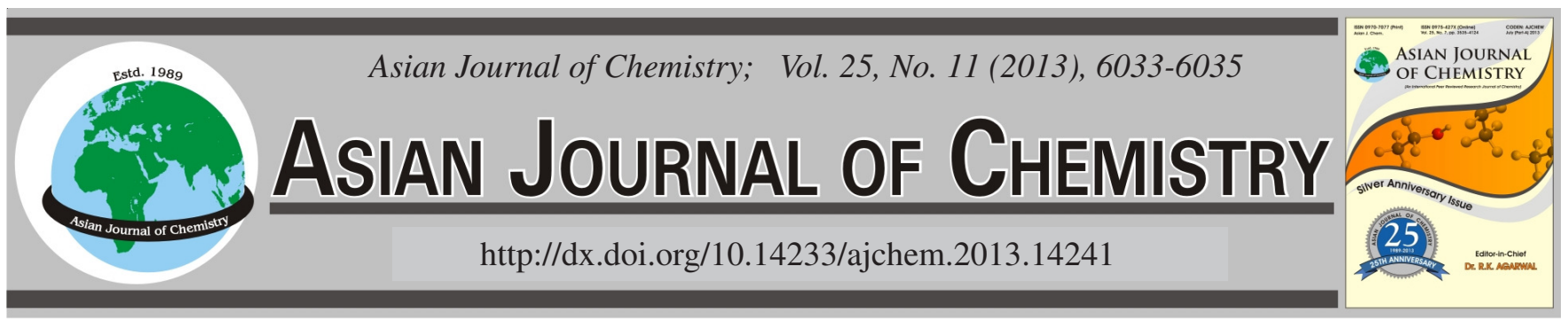

\title{
Adsorption of Zinc(II) from Aqueous Solution Using Poly(ethylene terephthalate)-Grafted-Methyl methacrylate/Acrylic Acid
}

FARIBORZ AZIZINEZHAD

Department of Chemistry, Varamin-Pishva Branch, Islamic Azad University, Varamin, Iran

Corresponding author: E-mail: fazizinejad@yahoo.com

\begin{abstract}
In the present study, graft copolymerization of methyl methacrylate, acrylic acid onto poly(ethylene terephthalate) fibers has been studied as a new adsorbent for the removal of $\mathrm{Zn}^{2+}$ ions from aqueous solutions by a batch equilibrium technique. The prepared copolymer was characterized by scanning electron microscopy, specific surface area, cation exchange capacity and point of zero charge $\left(\mathrm{pH}_{\mathrm{zpc}}\right)$. The best conditions for removal of $\mathrm{Zn}^{2+}$ recorded $(\mathrm{pH}=6.5, \mathrm{t}=20 \mathrm{~min}$, maximum adsorption capacity $=17.00 \mathrm{mg} / \mathrm{g})$.

Key Words: Adsorption, Grafting, Poly(ethylene terephthalate), Metyl methacrylate, Acrylic acid.
\end{abstract}

\section{INTRODUCTION}

Wastewater including heavy metal pollutants needs a treatment system which can remove these pollutants effectively. Heavy metals can be removed by different methods. Customary methods for removal of heavy metals from wastewater include ion-exchange, reverse osmosis, evaporation, electrolysis, membrane separation, adsorption, precipitation, ultrafiltration, oxidation, ozonation, coagulation and flocculation ${ }^{1-7}$. Polymerpropped reactive groups have been considered for the selective extraction processes of metal ions. Grafted poly(ethylene terephthalate) fibers can be improved undesirable properties of poly(ethylene terephthalate) such as low moisture regain, difficulty in dyeing, poor antistatic properties and because of high stability in acidic and basic media, fibers reactive agents have shown many advantages for removal of metal ions and dyes from wastewater ${ }^{8-16}$. Zinc toxicity from excessive englut is lower than other heavy metals. However, it may cause damage to various systems in the human body ${ }^{17,18}$. For this aim, according to our previous works the grafted poly(ethylene terephthalate) fibers have been synthesized by the mixture of methyl methacrylate and acrylic acid for removal of $\mathrm{Zn}^{2+}$ ions from aqueous solutions via batch adsorption method ${ }^{8,9}$.

\section{EXPERIMENTAL}

Methyl methacrylate and acrylic acid were supplied by BDH Co. of England and after purification were used in grafting procedure. For this aim, methyl methacrylate was washed three times with $5 \% \mathrm{NaOH}$, dried over $\mathrm{CaCl}_{2}$ and finally distilled in vacuum at $46^{\circ} \mathrm{C}$. Acrylic acid was vacuum distilled over a column filled with copper wires at $30^{\circ} \mathrm{C}$. Benzoyl peroxide $\left(\mathrm{Bz}_{2} \mathrm{O}_{2}\right)$ was recrystallized twice from the ethanol-chloroform (65\% vol. ethanol) mixture and dried in vacuum desiccators. Poly(ethylene terephthalate) fibers (stretch ratio 2, 30 filaments, 110dTex) were purchased from Amir Kabir University and Technology (Tehran). They were cut in bundles of $(0.1 \pm 0.01$ $\mathrm{g}$ ), Soxhlet -extracted for $6 \mathrm{~h}$ with acetone and dried at ambient temperature before grafting. All of reagents and solvents were high purity and supplied by Merck and doubly distilled water used in all experiments.

Grafting procedure: Grafting was accomplished in 100 mL Pyrex tube. The polymerization tube containing the $0.1 \mathrm{~g}$ poly(ethylene terephthalate) fiber, monomers (acrylic acid $30 \%$-methyl methacrylate $70 \%=0.1 \mathrm{~mol} / \mathrm{L}), 45 \mathrm{~mL}$ doubly distilled water, $5 \mathrm{~mL}$ acetone containing $4.0 \times 10^{-3} \mathrm{~mol} / \mathrm{L}$ benzoyl peroxide was added. In order to providing different graft yields, process was fulfilled at 5-60 min. For removal of undesirable homopolymers in media, the grafted fibers washed with water at room temperature for $24 \mathrm{~h}$ and Soxhlet extracted with toluene for $8 \mathrm{~h}$, dried and weighted. The per cent of grafted yield in fiber determined according to following equation:

$$
\mathrm{G}(\%)=\frac{\mathrm{W}_{\mathrm{g}}-\mathrm{W}_{0}}{\mathrm{~W}_{0}} \times 100
$$

$\mathrm{W}_{\mathrm{g}}$ and $\mathrm{W}_{0}$ are the weight of the grafted and original poly(ethylene terephthalate), respectively.

Adsorption studies: Adsorption experiments were fulfilled using $0.1 \mathrm{~g}$ of the grafted fibers with $20 \mathrm{~mL}$ solution of 
$\mathrm{Zn}^{2+}(100 \mathrm{mg} / \mathrm{L})$ in $250 \mathrm{~mL}$ Erlenmeyer flasks as functions of $\mathrm{pH}$, concentration and temperature at fixed agitation speed (150 rpm). After desirable time, the concentration of $\mathrm{Zn}^{2+}$ ions in the solution, after filtration was determined by using an atomic absorption spectroscopy with an air acetylene flame with hollow cathode lamp according to following equation:

$$
\mathrm{q}=\left(\mathrm{C}_{0}-\mathrm{C}\right) \frac{\mathrm{V}}{\mathrm{m}}
$$

where $\mathrm{C}_{0}$ and $\mathrm{C}$ denote the initial and equilibrium concentrations of $\mathrm{Zn}^{2+}$, respectively. $\mathrm{V}$ is the total volume of the solution (L), $\mathrm{m}$ is the adsorbent amount $(\mathrm{g})$ and $\mathrm{q}$ is the amount of the adsorbed $\mathrm{Zn}^{2+}(\mathrm{mg} / \mathrm{g})$.

\section{RESULTS AND DISCUSSION}

Characterization of adsorbent: The specific surface area of grafted fibers was ascertained from nitrogen adsorption isotherm according to BET method using a quantochrome Autosorb instrument. The specific surface area was $0.414 \mathrm{~m}^{2} /$ $\mathrm{g}$. This value is very negligible for investigation of adsorption process according to surface area and probably adsorption imputed to reactive groups $\left(-\mathrm{COOH},-\mathrm{COOCH}_{3}\right)$ which attached from monomers to the poly(ethylene terephthalate) chains. Cation exchange capacity (CEC) was determined according to copper ethylene diamine complex method and saturating by sodium acetate ${ }^{19,20}$. The results of both methods were the same and cation exchange capacity determined $(29.5 \mathrm{mg} / \mathrm{g}$ or $128.6 \mathrm{meq} / 100 \mathrm{~g})$. The point of zero charge $\left(\mathrm{pH}_{\mathrm{zpc}}\right)$ of reactive fibers measured at $\mathrm{pH} 3-9$. As shown in Fig. 1, the point of zero charge was $6.2^{21}$. Surface morphology was investigated using JEOL-JEM-100 CX II microscope. As shown in Fig. 2a-d, the adsorption of metal ions onto poly(ethylene terephthalate) fibers heterogeneity has been increased and the surface of fibers observed very rough.

Effect of pH: The effect of $\mathrm{pH}$ upon adsorption of $\mathrm{Zn}^{2+}$ ions has been determined from 1.5-9.0. As shown in Fig. 3, the optimum $\mathrm{pH}$ for removal of $\mathrm{Zn}^{2+}$ ions was found to be 6.5. At higher values of $\mathrm{pH}$, insoluble zinc hydroxide starts precipitating from the solution. At low $\mathrm{pH}$ values, the hydrogen and zinc ions on the sorption sites have been competed to each other $^{22}$

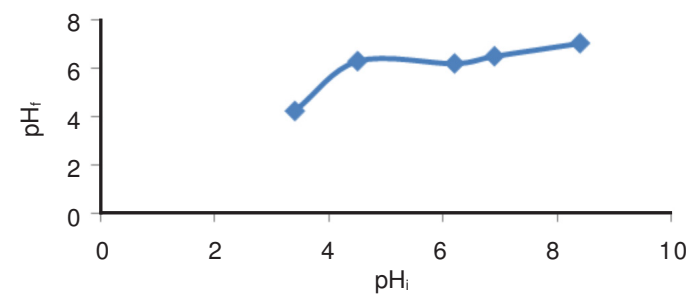

Fig. 1. Determination of the point of zero charge

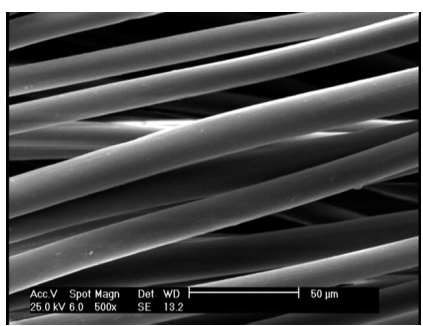

(a)

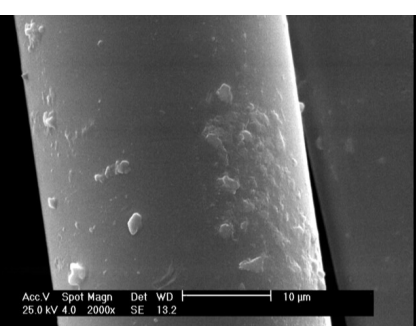

(b)

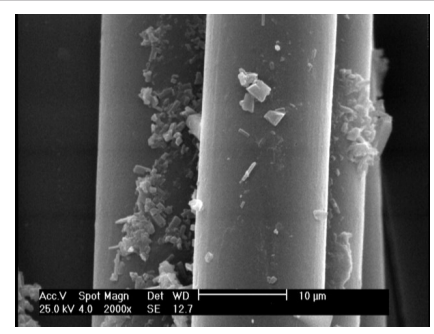

(c)

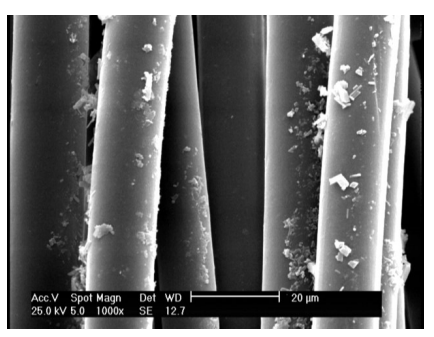

(d)
Fig. 2. SEM images of (a) ungrafted fibers (b) grafted fibers $(75 \%)(c, d)$ grafted poly(ethylene terephthalate) fibers containing $\mathrm{Zn}^{2+}$ ions at 2000 and $1000 \times$ magnifications, respectively

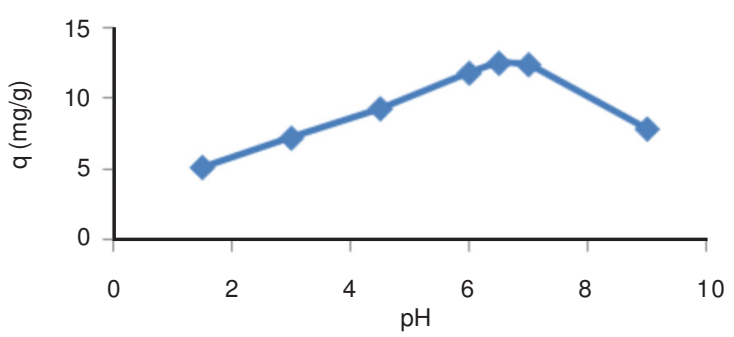

Fig. 3. Effect of the $\mathrm{pH}$ on the adsorption of $\mathrm{Zn}^{2+}$ onto $0.1 \mathrm{~g}$ modified poly(ethylene terephthalate) fibers $\left(\left[\mathrm{Zn}^{2+}\right]=100 \mathrm{mg} / \mathrm{L}\right.$, time $=75$ min, agitation rate $=150 \mathrm{rpm}, \mathrm{T}=298 \mathrm{~K}$, solution volume $=20 \mathrm{~mL}$ )

Effect of contact time: The effect of contact time on adsorption was studied from 5-75 min at the firm condition of other variables. As shown in Fig. 4, a rapid adsorption observed in $5 \mathrm{~min}$ and completed for $20 \mathrm{~min}$. After this time, the rate of adsorption decreased gradually. The maximum removal was $12.70 \mathrm{mg} / \mathrm{g}$ and it was reached in $75 \mathrm{~min}^{23}$.

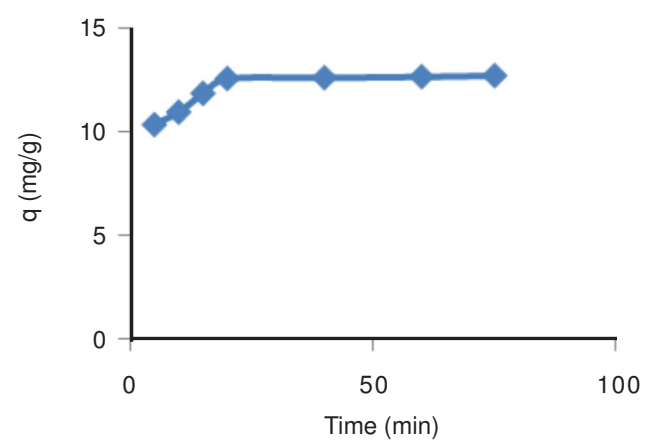

Fig. 4. Effect of contact time on the adsorption of $\mathrm{Zn}^{2+}$ onto $0.1 \mathrm{~g}$ modified poly(ethylene terephthalate) fibers, $\left(\left[\mathrm{Zn}^{2+}\right]=100 \mathrm{mg} / \mathrm{L}, \mathrm{pH}=6.50\right.$, agitation rate $=150 \mathrm{rpm}, \mathrm{T}=298 \mathrm{~K}$, solution volume $=20 \mathrm{~mL}$ )

Effect of adsorbent: Results of the effect of varying quantities of the reactive fibers $(\mathrm{G} \%=75 \%)$ from $0.05-0.20 \mathrm{~g}$ showed that an increasing in adsorption of $\mathrm{Zn}^{2+}$ ions. This is related to the reactive groups $\left(-\mathrm{COOH},-\mathrm{COOCH}_{3}\right)$ which attached to the poly(ethylene terephthalate) structure after grafting of acrylic acid and methyl methacrylate ${ }^{15}$ Fig. 5 .

Effect of adsorbate concentration: The effect of initial $\mathrm{Zn}^{2+}$ ions on the adsorption efficiency by methyl methacrylate/ acrylic acid- $g$-poly(ethylene terephthalate) fibers were studied by varying the initial concentration between 50 and $160 \mathrm{mg} / \mathrm{L}$. The best condition was observed at $17 \mathrm{mg} / \mathrm{g}$ using $160 \mathrm{mg} / \mathrm{L}$ aqueous solution (Fig. 6). 


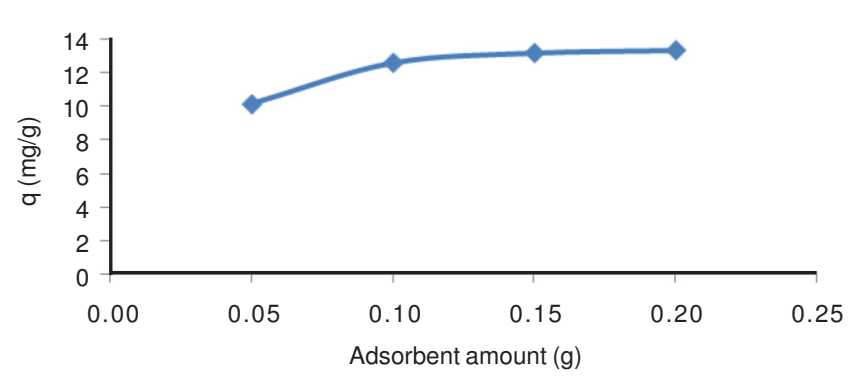

Fig. 5. Effect of adsorbent amount on the adsorption, $\left(\left[\mathrm{Zn}^{2+}\right]=100 \mathrm{mg} / \mathrm{L}\right.$, $\mathrm{pH}=6.50$, agitation rate $=150 \mathrm{rpm}, \mathrm{T}=298 \mathrm{~K}$, solution volume $=$ $20 \mathrm{~mL}$ )

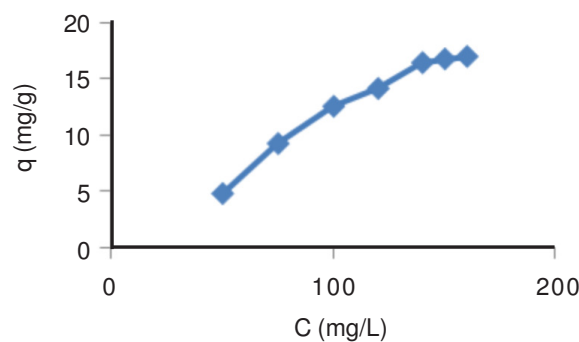

Fig. 6. Effect of initial $\mathrm{Zn}^{2+}$ ions concentration on the adsorption, (modified poly(ethylene terephthalate) fibers $=0.1 \mathrm{~g}, \mathrm{pH}=6.50$, agitation rate $=150 \mathrm{rpm}, \mathrm{T}=298 \mathrm{~K}$, solution volume $=20 \mathrm{~mL}$ )

Effect of grafting yield: The results of present study showed that by increasing the percentage of grafted yield, their adsorption capacity have been increased. The amount of 100 $\mathrm{mg} / \mathrm{L} \mathrm{Zn}^{2+}$ ions adsorbed per unit of fibers for 17,60 and $75 \%$ of the grafted products recorded 10.05, 12.56 and $13.50 \mathrm{mg} / \mathrm{g}$, respectively.

\section{Conclusion}

The results of present study showed that the poly(ethylene terephthalate)-g-methyl methacrylate/acrylic acid is an optimum adsorbent for the removal of $\mathrm{Zn}^{2+}$ from aqueous solution. The adsorption of $\mathrm{Zn}^{2+}$ is related to initial metal ion concentration, adsorbent amount, $\mathrm{pH}$ of the solution and the contact time. Maximum adsorption capacity of grafted poly(ethylene terephthalate) fibers for removal of $160 \mathrm{mg} / \mathrm{L}, \mathrm{Zn}^{2+}$ was recorded 17 $\mathrm{mg} / \mathrm{g}$ at $\mathrm{pH}=6.5$ after $20 \mathrm{~min}$.

\section{REFERENCES}

1. K.S. Rao, B. Sreedhar and K. Rajesh, Int. J. Environ. Prot., 28, 505 (2008).

2. Y. Bulut and Z. Tez, J. Hazard. Mater, 149, 35 (2007).

3. B.L. Martinus, C.V.C. Cruz, S.L. Aderval and C.A. Henriques, Biochem. Eng. J., 27, 310 (2006).

4. W.L.O. Chua, H.K.H. Lam and S.P. Bi, Chemosphere, 39, 2723 (1999).

5. A. Cabuk, T. Akar, S. Tunali and O. Tabak, J. Hazard. Mater., 136, 317 (2006).

6. A.I. Zouboulish, M. Loukidou and K.A. Matis, Process Biochem., 39, 909 (2004).

7. M. Tewari, P. Vasudevan and B.K. Guha, Biochem. Eng. J., 23, 185 (2005).

8. F. Azizinejad, M. Talu, M. Abdouss and M. Shabani, Iran. Polym. J., 14, 33 (2005).

9. F. Azizinezhad, R. Harutunyan and M. Abdouss, Asian. J. Chem., 22, 7803 (2010).

10. F. Azizinezhad, Asian. J. Chem., 23, 839 (2011).

11. F. Azizinezhad, Asian. J. Chem., 23, 899 (2011).

12. F. Azizinezhad, Alfa Univ. Int. J. Chem., 2, 123 (2011).

13. R. Coskun and C. Soykan, J. Polym. Res., 13, 1 (2006).

14. R. Coskun, J. Appl. Polym. Sci., 75, 766 (2000).

15. M. Arslan, Fibers Polym. J., 11, 177 (2010).

16. M. Arslan, Fibers Polym. J., 11, 325 (2010).

17. C. Lu and H. Chiu, Chem. Eng. Sci., 61, 1138 (2006).

18. C. Lu, H. Chiu and C. Liu, Ind. Eng. Chem. Res., 45, 2850 (2006).

19. V.C. Bushnell, Regional Lab, Bureau of Reclamation, Northwest Sci, 29 (2) (1955).

20. G.P. Gillman, Aust. J. Soil. Res., 17, 129 (1979).

21. S. Milonjic, A. Ruvarac and M. Susic, Thermochim. Acta, 11, 261 (1975).

22. N. Sakalar, M.H. Bilir, B. Acemioglu and M.H. Alma, Asian J. Chem., 22, 5649 (2010).

23. O. Abdelwaheb, Egypt. J. Aquat. Res., 33, 125 (2007). 